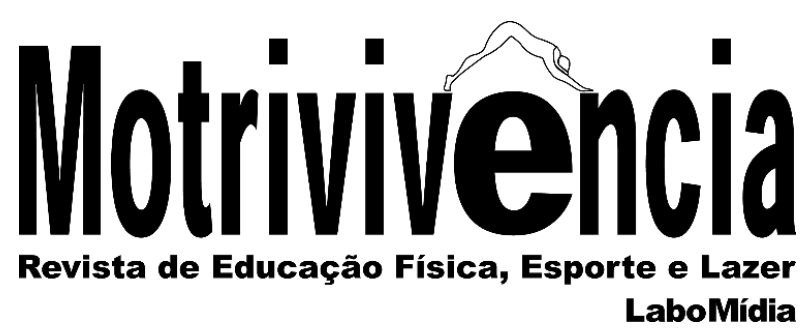

\title{
Educação Física escolar e futebol: o que pensam os alunos do ensino médio
}

\begin{abstract}
RESUMO
Este estudo objetivou identificar e apresentar concepções, crenças e contextos episódicos do futebol que marcaram a vida dos sujeitos participantes - adolescentes/ estudantes - como conteúdo e estratégia de ensino nas aulas de Educação Física no Ensino Médio. Os relatos foram obtidos a partir do método de participação coletiva de opiniões, denominado "roda de conversa" com estudantes de uma escola estadual em Cuiabá-MT. O estudo indicou a necessidade de se pensar o futebol num contexto sócio-histórico nas aulas de Educação Física e não somente como elemento esportivo explorado a partir da vivência técnica e tática. Assim, os alunos poderão se perceber como cidadãos críticos e participativos socialmente e não apenas reprodutores de habilidades físicas e/ou idealizações midiáticas.
\end{abstract}

PALAVRAS-CHAVE: Futebol; Educação física; Sociologia
Talita Ferreira

Mestre

Centro Universitário de Várzea Grande - UNIVAG,

Curso de Educação Física,

Várzea Grande, Mato Grosso, Brasil. tali-gabi@hotmail.com

(D) https://orcid.org/0000-0002-1825-0097

Evando Carlos Moreira

Doutor

Universidade Federal de Mato Grosso - UFMT, Departamento de Teoria e Fundamentação,

Cuiabá, Mato Grosso, Brasil.

ecmmoreira@uol.com.br

(1) https://orcid.org/0000-0002-5407-7930 


\title{
Physical Education at school and football: what think the students of high school
}

\begin{abstract}
This study aimed to identify and present conceptions, beliefs and football episodic contexts that marked the life of the participating subjects - teenagers / students - as content and teaching strategy in physical education classes in high school. The reports were obtained from the method of collective participation of opinions, called "conversation circle" with students from a state school in Cuiabá-MT. The study indicated the need to think about football in a social and historical context in physical education classes and not only as a sports element explored from the technical and tactical experience. Thus, students will be perceived as critical and participative citizens socially and not just copiers of the physical skills and media discourses.
\end{abstract}

KEYWORDS: Football; Physical education; Socioanthropological

\section{Educación Física escolar y fútbol: lo que los estudiantes de la escuela secundaria pensan}

\section{RESUMEN}

El estudio tuvo como objetivo identificar las concepciones, creencias y contextos episódicos de fútbol que marcaron la vida de los sujetos participantes - adolescentes / estudiantes - como el contenido y la estrategia de enseñanza en las clases de educación física en la escuela secundaria. Las declaraciones se obtuvieron a partir del método de la participación colectiva de opiniones, llamado "círculo de conversación" con estudiantes de una escuela pública en Cuiabá-MT. El estudio indicó la necesidad de pensar en el fútbol en un contexto histórico y social en las clases de educación física y no sólo como un elemento deportivo explorado partir de la experiencia técnica y táctica. Así, los estudiantes se dan cuenta de que son ciudadanos críticos y participativos socialmente y no sólo a los repetidores de habilidades físicas y / o discursos medios de comunicación.

PALABRAS-CLAVE: Fútbol; Educación física; Sociologia

\section{INTRODUÇÃO}


A produção acadêmica sobre o futebol num viés socioantropológico, começa a surgir no Brasil a partir da década de 1980. Assim, o esporte passa a ser entendido como um fenômeno social próprio de determinadas culturas (SODRÉ, 1977; TUBINO, 2001; HELAL, 2011). Contudo, especificamente na área da Educação Física, o futebol vem sendo apresentado de diversas maneiras, entre elas - e principalmente - como prática de atividade física para promoção da saúde; parte da aprendizagem e aprimoramento motor; como necessidade de socialização do indivíduo na escola e, pressupomos, o mais almejado pela sociedade de modo geral, a chance de ascensão por meio da profissionalização do esporte, tendo como diretriz a promoção de atletas e/ ou descoberta de novos talentos. Contudo, entende-se que outras formas de compreensão do fenômeno futebol precisam ser apresentadas e debatidas de maneira aprofundada.

Salun (2008) nos alerta para o fato de que, atualmente, não mais se admite a compreensão do fenômeno futebol apenas a partir do espetáculo, jogo ou campeonato, mas também, ressignificase o esporte a partir do atleta, dirigente, jornalista e/ ou torcedor.

Velho (2001) afirma que não existe vida social sem memória e que por sua vez, esta sofre mudanças e transformações causando alterações de ênfase e de destaque, mas sempre existe um referencial básico misto de valores e crenças que sustenta a comunicação entre indivíduos e grupos. Assim, o futebol pode ser entendido como parte constitutiva das identidades, o que de acordo com Bauman (2006), no mundo contemporâneo marcado pela diversidade, algumas podem ser escolhidas, mas outras são lançadas e impostas pelas pessoas em nossa volta e, por que não, pelas diversas mídias atuais.

Podemos afirmar que a inserção do futebol no campo esportivo não é mais suficiente para compreender a diversidade cultural e produção midiática de sentidos que justifiquem e sustentem o cenário escolar. Existem diálogos interdisciplinares no ambiente educacional que articulam o futebol a outras ciências, tais como a Antropologia, Sociologia e a Filosofia, por exemplo, além daquelas que se vinculam à música, literatura e outras artes (WISNIK, 2008).

Isto posto, o professor de Educação Física pode assumir o papel de agente social individual fornecendo sua concepção, articulação e mediação no processo de formação coletiva, tornando-se responsável pela formação de sujeitos críticos, autônomos e participativos.

Os meios de comunicação de massa (as mídias) assumem um papel de produção de modos de existência, organizando fluxos de acontecimento (espetáculos) sob formas dramáticas, sensacionalistas, criando e exacerbando identidades, produzindo emoções (COIMBRA, 2001).

Gomes (2001) percebe a mídia como construtora e propagadora de imaginários e identidades, responsabilizando-na pelos discursos diversos que emergem do cotidiano dos 
indivíduos, neste caso, do dia a dia de nossos alunos, haja vista que os meios de informação exercem influência constante e decisiva na cultura corporal de movimento desses jovens, informando e ditando formas, construindo novos significados e modalidades de entretenimento e consumo, especificamente no caso do futebol (venda de camisetas, jogos e souvenirs). Crianças e adolescentes consomem com maior assiduidade, resultando num processo de rivalização entre mídia, escola e família, ganhando assim, o papel de grande fomentadora de valores e atitudes (BETTI, 2001).

Nesse contexto, considerando que o futebol adquiriu nos últimos tempos aspectos que precisam ser analisados sob diferentes perspectivas, pretendemos ampliar as discussões sobre as diversas formas de apreender a realidade a partir dele, bem como a compreensão do exercício do poder e controle social midiático, de maneira a pensar nas interfaces entre a tecnologia, comunicação, estilo de vida e as novas maneiras de conceber as práticas corporais na atualidade, além da forma de disseminar esse conhecimento, especificamente no âmbito escolar e nas aulas de Educação Física.

Frente o exposto, surgiram as seguintes indagações: de que maneira o futebol é concebido por alunos do ensino médio nas aulas de Educação Física? De onde vêm esses saberes e conhecimentos futebolísticos? E, o primordial: compreender (ao menos “ouvir") qual o significado desse esporte na vida cotidiana de nossos alunos.

Diante de tantas possibilidades de abordagem no ensino do futebol no contexto da Educação Física, esta pesquisa teve como objetivo identificar e apresentar concepções, crenças e contextos episódicos do futebol que marcaram a vida dos sujeitos participantes, adolescentes/ estudantes, como conteúdo e estratégia de ensino nas aulas de Educação Física no Ensino Médio.

Limitamos este estudo ao Ensino Médio, pois durante os estágios realizados para conclusão do curso de licenciatura em Educação Física tem sido frequente a constatação por parte dos acadêmicos/ estagiários que a falta de interesse dos jovens e/ ou adolescentes pelas aulas dessa disciplina tem sido um entrave para a prática pedagógica e, quando há interesse, ele se manifesta somente quando o professor "libera" a bola de futebol.

Desse modo, o futebol foi problematizado e socializado entre um grupo de alunos do ensino médio a fim de que algumas questões pudessem ser debatidas e, posteriormente, se apresentassem como subsídios para trabalhos futuros de outros professores.

A partir das respostas obtidas, pôde-se realizar uma análise interpretativa que nos levou a reflexões inquietantes sobre o futebol e que serão apresentadas adiante.

\section{PROCEDIMENTOS METODOLÓGICOS}


A pesquisa caracteriza-se como qualitativa e descritiva, tendo em vista que permite observar, registrar, analisar e correlacionar fatos ou fenômenos sem a intenção de manipulá-los, descobrindo assim, a frequência de suas relações e conexões com outros fenômenos, sua natureza e caracterização (OLIVEIRA, 1999).

Como um estudo qualitativo, buscamos "a riqueza interpretativa, a contextualização do ambiente, dos detalhes e das experiências únicas" (SAMPIERI; COLLADO; LUCIO, 2006, p. 15).

Além disso, também podemos considerá-la como exploratória, já que, segundo Gil (1999), a pesquisa exploratória visa proporcionar maior familiaridade com o problema com vistas a torná-lo explícito ou a construir hipóteses.

O universo da pesquisa constituiu-se de uma escola estadual no município de Cuiabá, MT, de onde foram definidos os sujeitos do estudo: 16 alunos do $1^{\circ}$ ano do ensino médio, 14 do $2^{\circ}$ ano e 7 do $3^{\circ}$ ano, de ambos os sexos, perfazendo um total de 37 estudantes do período diurno, cujas atividades de Educação Física ocorriam no contraturno.

Quanto ao número de sujeitos (apenas 37 alunos), Minayo (1992) apontou que em pesquisa qualitativa, o critério para sua definição não é numérico, pois se considera uma amostra ideal aquela capaz de refletir a totalidade nas suas múltiplas dimensões, assim sendo, não se pretende generalizar o estudo com esta amostra, mas permitir e incitar discussões futuras acerca da temática.

Os sujeitos concordaram em participar do estudo a partir de uma apresentação prévia do objetivo da pesquisa e ainda, por ser esta uma das atividades propostas no planejamento de aulas do estágio supervisionado, o professor da escola responsável pelas aulas de Educação Física assinou um termo de aceite quanto à participação voluntária no estudo, permitindo que os dados observados e coletados fossem apresentados e disponibilizados em forma de pesquisa, mantendo o sigilo devido em relação à identidade dos alunos.

A proposta inicial pautava-se em ouvir os alunos numa roda de conversa, em que transitamos pelas seguintes questões/ abordagens:

1 - O que o futebol significa para vocês?

2 - Qual o principal atrativo do jogo de futebol?

3 - Qual a relação do futebol com as aulas de Educação Física?

4 - O que é preciso para ser um bom jogador de futebol?

5 - De onde vem seu conhecimento sobre o futebol? 
Assim, para que apresentássemos os resultados a seguir, selecionamos e agrupamos as categorizações sobressalentes inseridas no contexto futebolístico obtidas a partir da roda de conversa.

Segundo Nascimento e Silva (2009) a roda de conversa é uma técnica bastante utilizada nos processos de leitura e intervenção comunitária, consistindo num método de participação coletiva de debates e opiniões acerca de uma temática. Criam-se assim, espaços de diálogo, nos quais os sujeitos podem se expressar e, sobretudo, escutar os outros e a si mesmos. Tem como principal objetivo motivar a construção da autonomia dos sujeitos por meio da problematização, da socialização de saberes e da reflexão voltada para a ação. Envolve, portanto, um conjunto de trocas de experiências, conversas, discussão e divulgação de conhecimentos entre os envolvidos nesta metodologia.

Certamente, algumas questões surgem quando se escolhe a Roda de Conversa como técnica de pesquisa: Como garantir o rigor científico à investigação a partir de um encontro que parece tão informal? Como direcionar a pesquisa a partir da coleta de dados pela Roda de Conversa mantendo a autenticidade e espontaneidade da manifestação dos sujeitos no ambiente escolar, sem que isso comprometa eticamente a pesquisa?

Contudo, o cuidado com a técnica de coleta e o registro das informações foi fundamental para que as indagações anteriores fossem se esvaindo frente ao objetivo alcançado.

Houve momentos em que as opiniões expressas na Roda de Conversa sobre determinadas questões geraram polêmicas, em outras, se convergiram. Contudo, o papel do pesquisador como mediador foi fundamental para estabelecer um consenso e deixando claro aos alunos que as opiniões podem sim convergirem ou divergirem e é exatamente isso que mantém a interação entre os participantes. Nesse sentido, a técnica da Roda de Conversa pode lembrar aspectos da técnica do grupo focal, assumindo características semelhantes (GASKEL; 2002, p. 79).

A Roda de Conversa teve a duração média de 1h50, o equivalente a duas aulas de Educação Física no contraturno escolar, ou seja, no período vespertino. Participaram os 37 alunos convidados, a pesquisadora, um professor de outra disciplina que ficou responsável em gravar as manifestações dos alunos e uma observadora/relatora (aluna de um curso de graduação em Educação Física que estava realizando o estágio supervisionado na escola) que realizou o registro escrito num caderno de campo. A atividade ocorreu na quadra da escola, de forma a deixar o ambiente o mais natural possível para esse fim, já que os alunos estariam em aula de Educação Física nesse dia, pensou-se em trazer o ambiente da pesquisa para a quadra e não o contrário.

Um dos pesquisadores já havia estagiado na escola durante a graduação e conversou com os alunos, explicando o que fariam naquela tarde e qual o objetivo de não estarem "jogando" futsal 
como de costume. A autorização para a pesquisa já havia sido solicitada anteriormente, mas no momento da Roda de Conversa, explicamos a necessidade da gravação para registro e posterior transcrição das manifestações dos alunos, pedindo-lhes autorização para isso.

Optamos pela técnica de tratamento de dados denominada análise interpretativa que, ao contrário do método de análise de conteúdo, implica na interpretação das ideias apresentadas pelos sujeitos a partir da posição pessoal do autor, que deve extrapolar os sentidos expressos no texto através de sua leitura interpretativa embasada no referencial teórico do estudo (SEVERINO, 2000).

A partir das respostas, pôde-se aproximar as manifestações dos alunos às temáticas recorrentes em torno das vozes durante a conversa na aula de Educação Física escolhida para a realização da roda de conversa ganhando destaque as seguintes categorias: a romantização do jogador brasileiro; a necessidade da identificação com seus ídolos esportivos; o contexto sociocultural (ligado ao espetáculo e a alegria que envolve as pessoas em dias de jogo) e aspectos negativos, como a violência entre torcidas e a falta de ética de alguns jogadores. Há de se ressaltar que todos esses fatores estão relacionados a questões midiáticas que permeiam o esporte.

Após a realização da roda de conversa, gravação e transcrição das respostas, leitura das observações no caderno de campo e categorização em eixos temáticos, os dados foram apresentados, porém, para conservação do sigilo e preservação da identidade dos participantes da pesquisa, foi utilizada uma codificação dos sujeitos para a referência, utilizando-se as siglas A (aluno), M1 - F1, M2 - F2 ou M3 - F3, que podem significar "masculino do $1^{\circ}, 2^{\circ}$ ou $3^{\circ}$ ano" ou "feminino do $1^{\circ}, 2^{\circ}$ ou $3^{\circ}$ ano", seguidos pelos números fíctícios dados aos sujeitos, evidenciando em seguida as respostas que mais chamaram a atenção dos pesquisadores.

\section{RESULTADOS E DISCUSSÃO}

Apresentamos a seguir algumas respostas dos alunos que permeiam os condicionantes do futebol sugeridos nesta pesquisa e já apresentados na introdução e metodologia do presente artigo.

Indagando os alunos sobre o significado do futebol, o principal atrativo e o que era preciso para ser um bom jogador de futebol, as respostas apontaram para a romantização do jogo e do jogador brasileiro, percebida na idealização de que os bons jogadores de futebol possuem um talento inato, não precisam treinar arduamente, dispensa-se a disciplina como consequência da fama, dentre outras apresentadas.

Bracht (2005, p. 9) afirma que: "Sem dúvida, o esporte faz hoje parte, de uma ou de outra forma, da vida da maioria das pessoas em todo o mundo. [...] Hoje ele é, em praticamente todas as 
sociedades, uma das práticas sociais de maior unanimidade quanto a sua legitimidade social". Contudo, diante das respostas observadas, algumas vozes escolares produzem dúvidas no meio acadêmico em formação quanto aos valores humanos e sociais desse fenômeno, o futebol.

O futebol é um mundo cheio de coisas boas, né? Os jogadores têm mulheres [...], carros importados, fazem propagandas na televisão [...] vivem uma vida de Rei. Quem não queria ser jogador de futebol? Acha mesmo que eu queria ficar vindo pra escola, estudando igual um louco pra passar de ano, enquanto eu podia tá só jogando e ganhando muito dinheiro? Eu só precisava de sorte, é isso que eu acho (AM3.3).

O futebol perdeu seu caráter sagrado, não só na escola, mas na sociedade de modo geral, de acordo com Huizinga (2004, p. 220): “[...] esta ligação (do jogo) com o ritual foi completamente eliminada, o esporte se tornou profano, foi dessacralizado sob todos os aspectos e deixou de possuir qualquer ligação com a estrutura da sociedade".

Os alunos que falaram sobre o significado do futebol como jogo, deixou a desejar no aspecto "sociológico" das falas. Não foi possível perceber uma abordagem do futebol diante das características formais do jogo, a manifestação não propiciou o resgate de elementos teóricos consistentes que poderiam ter sido explorados durante a trajetória desses alunos pela educação básica, cujos preceitos do jogo se apresentassem como:

[...] uma atividade livre, conscientemente tomada como "não séria" e exterior à vida habitual, mas ao mesmo tempo capaz de absorver o jogador de maneira intensa e total. É uma atividade desligada de todo e qualquer interesse material, com o qual não se pode obter qualquer lucro, praticada dentro de limites espaciais e temporais próprios, segundo uma certa ordem e certas regras. Promove a formação de grupos sociais com tendência a rodearem-se de segredo e a sublinharem sua diferença em relação ao resto do mundo por meio de disfarces ou outros meios semelhantes. (HUIZINGA, 2004, p. 16).

Destaca-se, negativamente, que não se observou em nenhuma das respostas a preocupação em compreender como se processou o apego do brasileiro ou do mato-grossense por esse esporte, não há discussões, tampouco questionamentos, sobre as construções futebolísticas sobre as formas de vivenciar, praticar ou apenas entender o futebol brasileiro desde a "pátria em chuteiras" "famosa imagem brasileira cunhada pelo dramaturgo e escritor brasileiro Nelson Rodrigues (19121980) para expressar a relação que sempre percebemos entre a identidade nacional brasileira e Seleção Nacional de futebol" (HELAL, 2011, p. 17). Constata-se a ausência de falas que abordassem o esporte como valor social, símbolo nacional ou bem cultural. 
Analisando outras respostas verificou-se que existia uma tendência em se ressaltar os aspectos positivos e negativos de ser um jogador ou possuir alguma ligação (ainda que fíctícia) com esses símbolos esportivos:

O futebol pra mim significa que eu vou me divertir. É o esporte favorito de todo brasileiro [...] por mim eu só jogava futebol, nem precisava de outro esporte. Acho massa quando alguém fala que tô jogando igual a um famoso, o Neymar, o Messi, o Cristiano Ronaldo [...] me sinto mais poderoso ainda na partida. E se marco o gol então, viro o herói da escola pras meninas e respeitado pelos caras (AM1.4).

Eu não acompanho muito sobre os times, porque não gosto muito de futebol. Mas se alguém me perguntar sobre a vida dos jogadores, quem namora com quem, quem tá pegando quem, eu sei, claro. Todo dia a gente vê as fofocas nas revistas, na televisão, na internet [...] quem que não sabe, por exemplo, da vida do Neymar e da Bruna Marquezine? Só quem tá por fora do mundo. Até o David Beckham que nem é do Brasil a gente sabe da vida dele. Todo mundo sabe de tudo hoje graças a tecnologia, ainda bem, né? (AF1.2).

Notamos características de “ídolos-heróis” impressas nas respostas. Entretanto, tais caracterizações, tendo a mídia como veículo de propagação, transformam o universo futebolístico em terreno fecundo para a criação e disseminação de mitos sobre o esporte. Em algumas respostas percebem-se jogadores dotados de talento e carisma, com ênfases positivas em suas trajetórias (do menino pobre ao garoto rico altruísta), o que os singulariza e os diferencia dos demais, transformando-os em "heróis" para os adolescentes. Nesse sentido, somos convencidos de que "o futebol seria popular no Brasil porque ele permite expressar uma série de problemas nacionais, alternando percepção e elaboração intelectual com emoções e sentimentos concretamente sentidos e vividos" (DAMATTA, 1982, p. 40).

Não vejo tanta graça no futebol, mas que deve ser muito legal namorar um jogador, deve né? Imagine a vida de rainha? Todo mundo querendo tirar foto, viajando e conhecendo muitos países [...] você fica famosa junto com ele e nem tem que saber jogar futebol, né? (risos). E também, depois que eles têm bastante dinheiro, sempre voltam pra ajudar o lugar onde eles nasceram, constroem lugares pras crianças carentes, participam de eventos pra ajudar, doam o salário deles pras crianças que precisam. Acho legal, eles ficam ricos, mas tem consciência que o Brasil precisa deles (AF1.8).

De outro lado, existem os anti-heróis, figuras que desempenham o papel de "vilões" do esporte (RUBIO, 2001) durante as narrativas estudantis. Destacam-se na vida cotidiana dos alunos pelas notícias de atitudes polêmicas, mais do que pelo seu desempenho dentro de campo. A imagem pública construída está associada a atitudes e gestos que não são bem vistos pela sociedade, mas, ainda assim, gera euforia e uma espécie de "idolatria" nos adolescentes. 
Um bom jogador de futebol, pelo que eu vejo na televisão, sempre teve uma vida dura, sofrida [...] mas um dia, alguém descobre ele lá na favela jogando pelada e pronto! Fica rico da noite pro dia, todo mundo quer. Tem uns que eram feios quando eram pobres e agora que estão ricos as mulheres acham lindos. Acho um absurdo, mas é a realidade, nem treinar direito eles treinam, se acham os bons depois que ficam famosos. Tem homem que joga bem melhor que eles, mas não fica famoso (AF1.13).

Um bom jogador? Tem que ter dom em primeiro lugar. Cada um nasce sabendo fazer uma coisa, né? O jogador de futebol que fica famoso já nasce com isso. É um sortudo, isso sim [...] Claro que tem uns aí que Deus dá o dom e ele perde a chance. Entra no mundo das bebidas, das drogas, da mulherada e cai rapidinho. Tem um monte que a gente sabe, né? Só assistir TV ou entrar na internet e procurar que você vai ver (AM1.10).

Neira (2008) contribui com a discussão declarando a existência de obstáculos sociológicos dos currículos dos cursos de formação na área ao percurso curricular da formação inicial e continuada de professores, visto a maneira como os alunos percebem a relação entre o futebol e as aulas de Educação Física.

Desde que eu me lembro das aulas de Educação Física na escola é o futebol que comanda. Não adianta vir com joguinho, brincadeirinha [...] a gente quer jogar nosso futebol, é nosso momento de lazer poxa [...] o professor tem que entender. Já ficamos sentados todo o tempo vendo um monte de matéria chata e na única hora que é nossa, não podemos escolher nosso futebol? A gente não aceita não [...] tem que ser futebol pra gente se divertir, relaxar. As meninas podem escolher sempre o que querem fazer, então a gente também pode [...] e nós sempre queremos o futebol (AM1.3).

A professora já tentou fazer a gente gostar de outros esportes, mas não adianta, a gente até faz o que ela quer, mas no final tem que ter o futebolzinho pra relaxar [...] eu troco qualquer jogo, qualquer esporte pelo futebol, é a hora que os caras são todos parceiros, mesmo brigando no jogo, é uma briga normal, de jogo mesmo, entende? Ninguém vai sair dali e chamar o outro pra pancadaria na saída da escola, que nem a gente vê na TV. Lá o bicho é feio [...] todo jogo clássico tem morte e mesmo mostrando na televisão o povo continua indo, aí depois não tem do que reclamar, né? (AM2.4).

Se os diferentes currículos são influenciados por concepções de aprendizagem da cultura, da sociedade e dos conhecimentos que ensinam, diferenciando-se inclusive pela ênfase que dão a esses elementos (NEIRA, 2008), então, poderíamos pensar em aulas de Educação Física que envolvessem o futebol transformando-as num espaço de co-construção de conhecimentos diversos ligados a ele.

A juventude possui uma característica muito peculiar, ou seja, uma fase com muitas mudanças/ transformações tanto internas, como externas, físicas, psicológicas e sociais. Nesse sentido, podemos dizer que são sujeitos bastante vulneráveis, que estão a todo o momento em 
contato com diversas informações, muito destas transmitidas pela mídia (televisão, rádio, jornal, internet), sem muitas vezes apresentarem uma opinião formada sobre aquilo que está sendo enfatizado pela maioria dos veículos midiáticos.

Eu acompanho tudo pela internet e pela televisão. Em casa tem até briga quando minha irmã e minha mãe querem assistir outra coisa na hora do canal de esporte. Eu e meu pai que mandamos, não tem vez. Se eu não souber como que estão os times no campeonato, como eu vou poder zuar na escola? Além disso, a televisão me atualiza, a gente fica sabendo quanto tá valendo os passes dos jogadores, quem tá se vendendo pra outro time, virando a casaca, né [...] esses perdem meu respeito na hora. Tem jogador que só quer saber de dinheiro, a gente vê aí andando de iate, com mulherada, com bandidagem [...] aí vai lá, faz gol e fica tudo bem depois, o povo esquece (AM1.7).

Percebemos nas respostas que algumas imagens midiáticas já estão impressas nos alunos, são cópias de modelos discursivos advindos da televisão, das redes sociais, dentre outras mídias. Notamos a ausência nas respostas de uma perspectiva pautada pela antropologia e/ ou história, sobretudo pela aproximação que existe entre as áreas, respostas que demonstrem a compreensão do fenômeno esportivo sob a perspectiva dos de dentro, dos nativos, dos que sentem paixão ou amor pelo esporte (LOVISOLO, 2002).

E uma das decorrências do ensino tradicional, da abordagem que se faz do futebol nas aulas de Educação Física, é a que propicia a formação de reações e discursos estereotipados, isolados uns dos outros e aplicáveis somente às situações que convêm aos alunos em determinados contextos. Estes alunos apresentam, com frequência, apenas uma compreensão parcial dos fatos, resultando em respostas como as que seguem:

Meu conhecimento? Hum [...] a gente já nasce sabendo jogar, né? (risos). Brincadeira, acho que aprendi na rua quando era pequeno e os meninos mais velhos usavam a gente pra ficar catando a bola senão não podia jogar depois. Mas a gente também fica bom no futebol só jogando PS [PlayStation], porque a gente vê as jogadas e tenta fazer igual quando tá jogando. O futebol tá em todo lugar, tem que ser bem "mané" ou "menina", que tá perdoada, pra não saber sobre futebol (AM3.2).

Sobre o que tá acontecendo no mundo do futebol? Fácil, né? Antigamente meu pai ia no bar jogar sinuca e falar sobre futebol, hoje é só ficar meia hora na frente da televisão e no celular, né? A gente tem até grupo de futebol no whatsapp, é a maior xingação quando o time da gente perde, cada hora é um mandando uma imagem zuando o time do outro. Eu participo de três grupos no whats [...] um dos flamenguistas de Cuiabá, um aqui dos caras da escola e outro dos guris lá do bairro que sempre joga no fim de semana, aí um avisa o outro. (AM2.5).

Em geral, a prática do esporte, em evidência o futebol, é caracterizada pelos pressupostos da competição, da performance e da rigidez das regras. Soares et al. (1992) afirmam que o ensino do 
esporte nas aulas de Educação Física só tem sentido quando os alunos entendem os valores coletivos, bem como sua característica histórica, étnica, técnica, filosófica e política. Assim, compreende-se a prática a fim de transformá-la, já que o movimento humano, como forma de expressão cultural, carrega consigo elementos que não devem ser apenas praticados.

Posto isso, vê-se a necessidade, como nos diz Medina (2006), de uma verdadeira "revolução" na Educação Física escolar no intuito de se evitar uma aula sem significância, buscando, assim, novos subsídios para uma transformação nas ações práticas por parte dos professores de Educação Física mudando a realidade que se apresenta. Caso contrário, o futebol continuará a ser um esporte reconhecido apenas pela ligação ao espetáculo e a alegria que envolve as pessoas em dias de jogo, além de atividade performática nas aulas de Educação Física:

Futebol é o esporte dos meninos. Tá, eu sei que não tem mais tanto preconceito, mas mesmo assim, a maioria que gosta são meninos [...] e as meninas que gostam sofrem preconceitos, acham que elas não são femininas. Eu não jogo futebol, mas assisto e tenho meu time, porque toda a turma se reúne em dia de jogo e quem não tem sua camisa de time pra desfilar fica de fora. É legal quando a turma da escola se reúne pra assistir, vira uma festa, né? O jogo mesmo ninguém vê, mas o futebol une a sala (AF1.2).

Independentemente da faixa etária ou do grupo social investigado, parece evidente que a torcida é parte fundamental para se compreender os aspectos sedutores do futebol, como afirma Sodré (1977, p. 141): “A torcida [...] faz parte necessária do show”.

Já acostumamos com o futebol nas aulas. Sabemos que se os meninos não jogarem eles ficam loucos e atrapalham toda a aula, faz tudo de qualquer jeito. Mas não acho que somos obrigadas a jogar futebol também, gostamos mais de jogar em roda ou ficar conversando nos bancos [...] Mas uma coisa é certa: precisamos do futebol fora da escola, porque quando a galera faz um churras ou se reúne em algum barzinho pra assistir junto, aí todo mundo tem que ter um time pra torcer, até pra ser convidado, né? Eu acho legal o futebol só pra estar junto com os amigos (AF1.5).

Finalizando as discussões a partir dos pressupostos apresentados, temos o dever de exprimir a ideia com a qual coadunamos de que, contrariamente ao que se mostra, o futebol nas aulas de Educação Física não pode ser apenas uma área de ordem motora e fundamentos técnicos, mas sim, um meio pelo qual seja possível estudar seu enraizamento social e sua significação cultural inserida no contexto escolar, como se lê em Gonçalves (1994, p.141):

O movimento humano é mais do que o resultado da atuação das forças fisiológicas ou biomecânicas, ou de um processo de aprendizagem motora, e sim é o homem como um todo que se movimenta. A Educação Física não deve priorizar apenas o aspecto físico. Neste sentido o profissional deve estar sempre voltado para o 
desenvolvimento global dos seus alunos, tornando-os seres conscientes e críticos, inseridos nesta sociedade tão abrangente da qual ele é parte integrante e resultante.

Por isso, não há como negar o futebol "midiatizado" até mesmo nas escolas, sem nenhum sentido de questionamento quanto às qualidades extraordinárias do esporte. Principalmente, após a realização da Copa do Mundo no Brasil e, especificamente, numa escola situada numa cidade que sediou quatro jogos de um evento deste porte, e que ainda, lida com o ônus e o bônus desse processo.

Impossível seria pensar que uma onda de euforia não tome conta desses adolescentes. Entretanto, há de se cuidar para que esses alunos não fiquem "presos" a essa catarse coletiva que nos prende ao futebol, espera-se que não fiquemos à espera de vitórias externas para se discutir a temática que, internamente, vem trazendo preocupações passíveis de derrotas as nossas escolas.

\section{CONSIDERAÇÕES FINAIS}

Parece-nos que o esporte, particularmente neste estudo, o futebol, é um objeto de desejo de consumo, desde o menino que quer ser comparado ao jogador famoso até a menina que se contentaria em ser a namorada do tal jogador. Temos a impressão de que é o "atleta/ jogador" e não mais o esporte em si que faz com que o indivíduo, torcedor ou não, acompanhe com afinco a temática futebolística em questão.

Sinalizamos para o fato de que a formação acadêmica em Educação Física apresenta-se em (in) consonância com o discurso futebolístico sociocultural vigente. Há, de modo geral, um grande abismo comunicacional entre os professores e alunos, além de uma disparidade entre os saberes/ conhecimentos "necessários" PARA o professor e os "requeridos" PELO aluno/ indivíduo/ brasileiro, constituído por uma identidade nacional, inserido num meio social construído por uma infinidade de outros saberes, parte de uma diversidade cultural.

Assim, ao ouvir as respostas dos alunos que foram sujeitos dessa pesquisa, pôde-se refletir acerca da escassez de estudos sociológicos sobre o esporte, especificamente sobre o futebol, na escola, concluindo que grande parte dos conhecimentos veiculados no espaço escolar ainda são restritos a uma função reprodutivo/ transmissora de reflexões já constituídas.

Não foi possível verificar ainda o avanço do debate e estudos sociológicos sobre o futebol na escola. Contudo, esperamos que este trabalho estimule e contribua para futuras iniciativas de pesquisa que utilizem o aspecto sociológico em sua investigação, já que este estudo indicou a necessidade de se pensar nesse esporte num contexto sócio-histórico nas aulas de Educação Física 
escolar, e não somente como elemento esportivo a ser explorado, para que os alunos percebam que não são apenas reprodutores de meras habilidades físicas, mas identidades múltiplas que podem ser reconhecidos como cidadãos críticos, conscientes e participativos socialmente.

Outras questões e análises relevantes à sociologia do esporte não puderam ser apontadas/ realizadas neste momento no presente texto, mas, não se pode negar a existência estampada do controle social que a mídia exerce nos alunos. Desse modo, longe de um discurso contrário à utilização da mídia na atuação docente, o que se pretende é suscitar que pensemos urgentemente nas interfaces entre Educação Física, futebol, tecnologia, comunicação, estilo de vida e as tantas novas maneiras de conceber as práticas corporais na atualidade, bem como a melhor forma de disseminar esse conhecimento no ambiente escolar, dando ênfase, claro, na faixa etária que se encontra ainda em formação intelectual nas escolas.

A partir do que foi apresentado, podemos considerar que o futebol, como conteúdo das aulas de Educação Física, deve estar inserido em um contexto maior, abrangendo desde sua história, evolução, contextualização social, política e econômica, fundamentos, técnicas e regras, enfim, é necessário que se pesquise e busque as raízes da práxis, uma vez que, ainda que ele seja um esporte mundialmente conhecido, está vinculado a uma concepção de mundo, de sociedade, de ser humano, de educação e de cultura de cada local.

\section{REFERÊNCIAS}

BAUMAN, Zygmunt. Identidade. Rio de Janeiro: Jorge Zahar, 2006.

BETTI, Mauro. Mídias: aliadas ou inimigas da educação física escolar. Motriz. São Paulo, v. 7, n. 2, p. 125-129, jul./dez., 2001.

BRACHT, Valter. Sociologia crítica do esporte: uma introdução. Ijuí, RS: Unijuí, 2005.

BRACHT, Valter. Educação física e ciência: cenas de um casamento (in) feliz. Ijuí, RS: Unijui, 1999.

COIMBRA, Cecília Maria Bouças. Mídia e produção de modos de existência. Psicologia: teoria e pesquisa, Brasília, DF, v. 17, n. 1, p. 1-4, jan./ abr., 2001.

DAMATTA, Roberto. Universo do futebol: esporte e sociedade brasileira. Rio de Janeiro: Pinakotheke, 1982.

DARIDO, Suraya Cristina. Apresentação e análise das principais abordagens da educação física escolar. Revista brasileira de ciências do esporte, Florianópolis, SC, v. 20, n. 1, p. 58-66, set., 1998. 
GASKELL, George. Entrevistas individuais e grupais. In: BAUER, Martin W.; GASKELL, George; (Orgs.). Pesquisa qualitativa com texto, imagem e som: um manual prático. Petrópolis: Vozes, 2002, p. 64-89.

GOMES, Paola Basso Menna Barreto. Mídia, imaginário de consumo e educação. Educação \& Sociedade, Campinas, SP, v. 22, n. 74, p. 191-207, abr., 2001.

GIL, Antonio Carlos. Métodos e técnicas de pesquisa social. São Paulo: Atlas, 1999.

GONÇALVES, Maria Augusta Salim. Sentir, pensar e agir: corporeidade e educação. Campinas, SP: Papirus, 1994.

HELAL, Ronaldo. Futebol e comunicação: a consolidação do campo acadêmico no Brasil. Comunicação, mídia e consumo. São Paulo, v. 8, n. 21, p. 11-37, mar., 2011.

HUIZINGA, Johan. Homo ludens: o jogo como elemento da cultura. São Paulo: Perspectiva, 2004.

LOVISOLO, Hugo. Sociologia do esporte: viradas argumentativas. Encontro Anual da Anpocs, 26. Anais... Caxambu, MG, p. 1-16, 2002. Disponível em: https://www.anpocs.com/index.php/papers26-encontro/gt-23/gt06-7/4377-hlovisolo-sociologia/file. Acesso em: 07 de jun. 2016.

MEDINA, João Paulo Subirá. A educação física cuida do corpo e..."mente": bases para a renovação e transformação da educação física. Campinas, SP: Papirus, 2006.

MELO, Victor Andrade de. Reflexão sobre a história da educação física no Brasil: uma abordagem historiográfica. Movimento. Porto Alegre, RS, v. 3, n. 4, p. 41-48, 1996.

MINAYO, Maria Cecília de Souza. O desafio do conhecimento: pesquisa qualitativa em saúde. São Paulo: Hucitec/ Rio de Janeiro: Abrasco, 1992.

NASCIMENTO, Maria Anezilany Gomes do; SILVA, Cícero Nilton Moreira da. Rodas de conversa e oficinas temáticas: experiências metodológicas de ensino-aprendizagem em geografia. Encontro Nacional de Prática de Ensino em Geografia, 10. Anais... Porto Alegre, RS, p. 1-11, 2009. Disponível em: http://www.agb.org.br/XENPEG/artigos/Poster/P\%20(36).pdf Acesso em: 07 de jun. 2016.

NEIRA, Marcos Garcia. Formação para a docência: o lugar da educação física na educação básica. In: SCHNEIDER, Omar; GRUNENNVALDT, José Tarcísio; KUHN, Roselaine; RIBEIRO, Sérgio Dorensk Dantas. Educação física, esporte e sociedade: temas emergentes. São Cristóvão, SE: UFS, 2008.

NEIRA, Marcos Garcia; NUNES, Mario Luiz Ferrari. Pedagogia da cultura corporal: crítica e alternativas. São Paulo, SP: Phorte, 2008.

OLIVEIRA, Silvio Luiz de. Metodologia da pesquisa. In: OLIVEIRA, Silvio Luiz de. Tratado de metodologia científica: projetos de pesquisa, tgi, tcc, monografias, dissertações e teses. São Paulo: Pioneira, 1999.

RUBIO, Katia. O atleta e o mito do herói. São Paulo: Casa do Psicólogo, 2001. 
SALUN, Alfredo Oscar. Palestra Itália e Corinthians: quinta coluna ou buona gente? 2008. $282 \mathrm{f}$. Tese (Doutorado em História Social). Faculdade de Filosofia, Letras e Ciências Humanas, Universidade de São Paulo, São Paulo, 2008.

SAMPIERI, Roberto Hernandez; COLLADO, Carlos Fernández; LUCIO, María del Pilar Batista. Metodologia de pesquisa. São Paulo: McGraw Hill, 2006.

SEVERINO, Antonio Joaquim. Metodologia do trabalho científico. São Paulo: Cortez, 2000.

SOARES, Carmen Lúcia et al. Metodologia do ensino de educação física. São Paulo: Cortez, 1992.

SOARES, Carmen Lúcia. Educação física: raízes européias e Brasil. Campinas, SP: Autores Associados, 1994

SODRÉ, Muniz. Futebol, teatro ou televisão. In: SODRÉ, Muniz. O monopólio da fala. Petrópolis, RJ: Vozes, 1977.

VARGAS, Angelo Luiz. Desporto: fenômeno social. Rio de Janeiro: Sprint, 1995.

VELHO, Gilberto. Memória, cultura e sociedade. In: LEIBING, Anete; LÜHL-BENNINGHOFF, Sibylle. (Orgs.). Devorando o tempo: Brasil, o país sem memória. São Paulo: Mandarim, 2001.

WISNIK, José Miguel. Veneno remédio: o futebol e o Brasil. São Paulo: Companhia das Letras, 2008.

\section{NOTAS DE AUTOR}

\section{AGRADECIMENTOS}

Não se aplica.

\section{CONTRIBUIÇÃO DE AUTORIA}

Não se aplica.

\section{FINANCIAMENTO}

Não se aplica.

\section{CONSENTIMENTO DE USO DE IMAGEM}

Não se aplica.

\section{APROVAÇÃO DE COMITÊ DE ÉTICA EM PESQUISA}

Não se aplica. 


\section{CONFLITO DE INTERESSES}

Não se aplica.

\section{LICENÇA DE USO}

Os autores cedem à Motrivivência - ISSN 2175-8042 os direitos exclusivos de primeira publicação, com o trabalho simultaneamente licenciado sob a Licença Creative Commons Attribution Non-Comercial ShareAlike (CC BY-NC SA) 4.0 International. Estra licença permite que terceiros remixem, adaptem e criem a partir do trabalho publicado, desde que para fins não comerciais, atribuindo o devido crédito de autoria e publicação inicial neste periódico desde que adotem a mesma licença, compartilhar igual. Os autores têm autorização para assumir contratos adicionais separadamente, para distribuição não exclusiva da versão do trabalho publicada neste periódico (ex.: publicar em repositório institucional, em site pessoal, publicar uma tradução, ou como capítulo de livro), com reconhecimento de autoria e publicação inicial neste periódico, desde que para fins não comerciais e compartilhar com a mesma licença.

\section{PUBLISHER}

Universidade Federal de Santa Catarina. Programa de Pós-Graduação em Educação Física. LaboMídia - Laboratório e Observatório da Mídia Esportiva. Publicado no Portal de Periódicos UFSC. As ideias expressadas neste artigo são de responsabilidade de seus autores, não representando, necessariamente, a opinião dos editores ou da universidade.

\section{EDITORES}

Mauricio Roberto da Silva, Giovani de Lorenzi Pires, Rogério Santos Pereira.

\section{HISTÓRICO}

Recebido em: Abril/2018

Aprovado em: Julho/2018 